\title{
Catalytic Enantioselective Diels-Alder Reactions of Acrylate Derivatives in the Presence of Chiral Binap-Palladium Complexes
}

\author{
Young Ku Kang and Dae Young Kim* \\ Department of Chemisty' Soonchuhy'ang University' Asan, Chnngham 336-745, Korea. 'E-mail: dyoung@schac.kr \\ Received September 1, 2008
}

Key Words : Chiral palladium complexes, Diels-Alder reactions, Achiral templates, Asynunetric reactions

The Diels-Alder reaction is one of the most efficient $\mathrm{C}-\mathrm{C}$ bond-forming reactions that permit the rapid development of molecular complexity. ${ }^{1}$ It allows the stereoselective formation of as many as four stereogenic centers, and as many as three carbocyclic rings in the intramolecular and transannular variations. For this reason, the recent development of highly enantioselectice Diels-Alder reactions represents a great advance in synthetic chemistry. ${ }^{1}$ Remarkable progress toward this goal has been achieved through the use of both chiral auxiliaries ${ }^{2}$ and chiral catalysts such as metal complexes ${ }^{3}$ and organocatalysts. ${ }^{4}$ A large number of Lewis acid catalysts based on aluminum, boron, magnesium, and transition metals have been used for this purpose. ${ }^{3}$ Recently, the potential of late transition metal such as palladium-based chiral Lewis acids has been explored in detail for DielsAlder reactions. "While several efficient asymmetric DielsAlder reactions using chiral Lewic acids have been developed, a drawback is that most Lewis acids are unstable in the presence of water and even sensitive to moisture. Therefore, the development of Diels-Alder reaction using moisture-stable chiral Lewis acid is still in great demand.

As part of research program related to the development of synthetic methods for the enantioselective construction of stereogenic carbon centers, ${ }^{6}$ we report the catalytic enantioselective fluorination and amination of ester derivatives promoted by air- and moisture-stable chiral palladium complexes. ${ }^{7}$ In this letter, we wish to report the Diels-Alder reactions of acrylate attatched to a two-point donor in the presence of chiral palladium complexes $1 .^{8}$

$$
\begin{gathered}
{\left[{ }_{\mathrm{P}}^{\mathrm{P}} \mathrm{NCMe}^{2+} \mathrm{OH}_{2}\right.} \\
\text { 1a: } \mathrm{X}=\mathrm{BF}_{4} \\
\text { 1b: } \mathrm{X}=\mathrm{OTf} \\
\text { 1c: } \mathrm{X}=\mathrm{PF}_{6} \\
\text { 1d: } \mathrm{X}=\mathrm{SbF}_{6}
\end{gathered}
$$

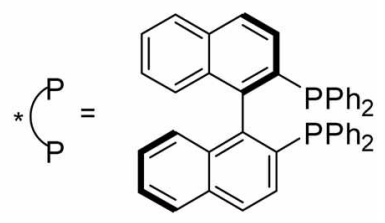

To determine suitable reaction conditions for the catalytic enantioselective Diels-Alder reactions of acrylates, we initially investigated the reaction system with cyclopenatadiene 3 and acrylate derivatives 2 capable of forming six- or fivemembered chelate with the chiral $(R)$-Binap-palladium complexes $1 c$ in dichloromethane. The oxazolidinone template 2a showed excellent diasteroselectivity (endo/exo 98/2) and enantioselectivity, $99 \%$ ee (entry 1 ). Replacement of the ring oxygen in 2 a by a methylene group, the pyrrolidinone template $2 \mathrm{~b}$, gave slightly lower reactivity and selectivity (entry 2). The $N$-benzoyl and $N$-2-pyridyl templates $2 \mathrm{c}$-2d were less reactive and less selective as compared to template $\mathbf{2 a}$ (entries 3 and 4). Peplacement of benzoyl group in 2c, with phosphoryl group as in $2 \mathrm{e}$, led to lowed reactivity. Two

Table 1. Enantioselective Diels-Alder reaction of acrylate templates

Entry

"Enantiopurity of 4 was determined by HPLC analysis with (hiralcel $\mathrm{OD}-\mathrm{H}$ (for $4 \mathbf{a}, \mathbf{4 f}$ ). $\mathrm{OJ}$ (for $\mathbf{4}$ ), Cliralpak $\mathrm{AD}$ (for $\mathbf{4 b}$ ), and $\mathrm{AD} \cdot \mathrm{H}$ (for 4d. 4e, 4g) column. "Absolute configuration was determined by comparison of the optical rotation and the HPLC retention time of the corresponding adduct with literature salue. in "Dephosphorylation product was obtained as major product. "Desilylation product was obtained as major product. 
Table 2. Enantioselective Diels-Alder reaction of cyclopentadiene 3 with dienophile $2 \mathrm{a}$ in presence of $\mathrm{Pd}$ complexes

\begin{tabular}{|c|c|c|c|c|c|}
\hline \multicolumn{2}{|c|}{$2 a$} & 3 & & & $4 a$ \\
\hline Entry & Cat. & Time (h) & Yield $(\%)$ & Endolero & $\operatorname{Ee}(\%)^{4}$ \\
\hline l & $1 \mathbf{a}$ & 32 & 71 & $95: 5$ & $99\left(S^{\prime}\right)$ \\
\hline 2 & $1 \mathrm{~b}$ & 45 & 32 & $96: 4$ & $87(5)$ \\
\hline 3 & 1c & 5 & 97 & $98: 2$ & $99(S)$ \\
\hline 4 & ld & 45 & 40 & $97 / 3$ & $90(S)$ \\
\hline 5 & lc & 19 & 89 & $95 / 5$ & $99(S)$ \\
\hline
\end{tabular}

"Enantiopurity of 4 a was determined by HPLC analy sis with Chitalcel $\mathrm{OD}-\mathrm{H}$ colunu. "Absolute configuration was detemined by comparison of the optical rotation and the HPLC retention time of the corresponding ester with literature value." Reaction carried out using 5 mol\% of catalyst.

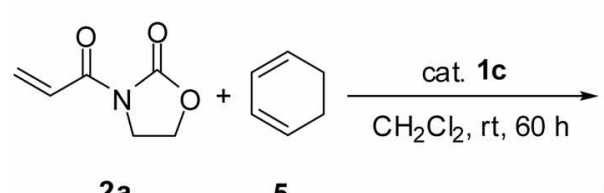

2a

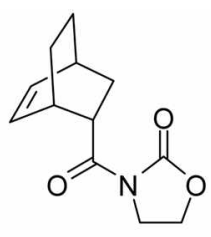

6a $65 \%$ yield endo:exo $=97: 3$ $95 \%$ ee
Scheme 1

templates $\mathbf{2 f}$ and $\mathbf{2 g}$ capable of five-membered chelate with the palladium complex were examined. Both of these templates showed only moderate selectivity (entries 6 and 7) as compared to reactions with acrylates derived $2 \mathbf{a}-\mathbf{2 d}$

Catalysts $1 \mathrm{a}$ and $1 \mathrm{c}$ were more effective than other catalysts (Table 2, entries 1-4). The present catalytic system tolerates catalyst loading down to $5 \mathrm{~mol} \%$ without compromising either the yield or enantioselectivity (entries 3 and 5).

Another diene, 1,3-cyclohexadiene (5) was also examined in this reaction with 3-acryloxy-2-oxazolidinone (2a) and the result showed excellent diasteroselectivity, $97 / 3$ endo/ exo ratio in $65 \%$ yield, the endo isomer showed high enantioselectivity, 95\% ee (Scheme 1). Unfortunately, the reaction of $\beta$-alkyl substituted acryloyl derivatives with cyclopentadiene was not preceded in this condition.

In conclusion, we have developed a highly efficient catalytic enantioselective Diels-Alder reaction of acrylates using air- and moisture-stable chiral palladium complexes. The desired Diels-Alder adducts were obtained in good to high yields, and excellent enantioselectivities (up to 99\% ee) were observed. Further details and application of this DielsAlder reaction will be presented in due course.

Acknowledgments. This research was financially supported by the Ministry of Education. Science. Technology (MEST) and Korea Industrial Technology Foundation (KOTEF) through the Human Resource Training Project for Regional Innovation.

\section{References and Notes}

1. (a) Comprehensive Organic Sinhesis; Trost, B. M., Fleming, I., Eds.; Pergamon: Oxford, 1991; Vol 5, Oppolzer, W., in Chapter 4.1, and Roush, W. R., in Chapter 4.4. (b) Kagan, H. B.; Riant, O. Chem. Rev. 1992, 92, 1007. (c) Fache, F.; Schulz, E.; Tommasino, M. L.; Lemaire, M. Chem. Rev 2000, 100, 2159.

2. (a) Evans, D. A.; Chapman, K. T.; Bisalha, J. J. Am. Chem. Soc. 1988, 110, 1238. (b) Evans, D. A.; Chapman, K. T.; Bisaha, J. $J$. An. Chen. Soc. 1984, 106, 4261. (c) Oppolzer, W.; Chapuis, C.; Bernardinelli, G. Helv: Chin. Acta 1984, 67, 1397.

3. (a) Evans, D. A.; Jolnson, J. S. In Comprehensive Aslmmetric Catalvisis; Jacobsen, E. N., Pfaltz, A., Yanamoto., Eds, Springer: Berlin, 1999; Vol 3. (b) Crcloaddition Reactions in Organic St:nhesis; Kobayashi, S., Jørgensen, K. A., Eds.; Wiley-VCH: New York, 2002. (c) Lewis Acils in Organic Stmhesis; Yamamoto, H., Ed.; New York, 2000; Vols. 1 and 2. (d) Evans, D. A; Miller, S. J.; Lectka, T.; Matt, P. V. J. Am. Chem. Soc, 1999 , 121, 7559. (e) Ryu, D. H.; Lee, T. W. Corey, E. J. J. Am. Chem. Soc. 2002, 124, 9992. (t) Jarvo, E. R. B.; Lawrenece, M; Jacobsen, E. N. Angen: Chen. In. Ed. 2005, 44, 6043.

4. (a) Northrup, A. B.; Mac.Villan, D. W. C. J. Am. Chem. Soc. 2002, 124, 2458. (b) Huang, Y.; Unni, A. K.; Thadani, A. N.; Rawal, V. Nature 2003, 424, 146. (c)Wilson, R. M.; Jen, W. S.; MacMillan, D. W. C. $J$. Am. Chem. Soc. 2005, 127, 11616. (d) Lemay, M: Ogilvie, W. W. Org. Lett. 2005, 7, 4141. (e) Sakakura, A.; Suzuki, $\mathrm{K}$; Nakano, K.; Ishihara, K. Org. Lett. 2006, 8, 2229.

5. (a) Oi, S.; Kashiwagi, K.; Inoue, Y. Tetrchedron Lett. 1998, 39, 6253. (b) Mikami, K.; Aikawa, K.; Yusa, Y.; Hatano, M. Org. Lett. 2001, 4, 91. (c) Becker, J. J.; Van Orden, L. J.; White, P. S.; Gagne, M. R. Org. Lett. 2002, 4, 727. (d) Pelz, K. A.: Whithe, P. S.: Gagne, M. R. Organometallics 2004, 33, 3210. (e) Nakano, H.; Tsugawa, N.; Fujita, R. Tetrohedron Lett. 2005, 46, 5677. (f) Manchenn̄o, O. G.; Arrayẫ, R. G; Carretero, J. C. Orgunonetallics 2005, 24, 557. (g) Takahashi, K.; Nakano, H.; Fujita, R. Chem. Commin. 2007, 263.

6. (a) Kin, D. Y.; Park, E. J. Org. Letr. 2002, 4, 545. (b) Park, E. J.; Kim, M. H.; Kim, D. Y. J. Org. Chem. 2004, 69, 6897. (c) Jung, S. $\mathrm{H}$; Kim, D. Y. Tetrohedron Lett. 2008, 49, 5527

7. (a) Kim, S. M.; Kim, H. R.; Kim, D. Y. Org. Lett. 2005, 7, 2309. (b) Kim, H. R.; Kim, D. Y. Tetrahedron Lett. 2005, 46, 3115. (c) Kim, S. M.; Kang, Y. K.; Lee, K.; Mang, J. Y.; Kim, D. Y. Bull. Korean Chem. Soc. 2006, 27, 423. (d) Kang, Y. K.: Cho, M. J.; Kim, S. M.; Kim, D. Y. Sylett 2007, 1135 , (e) Cho, M. J.; Kang, Y. K.; Lee, N. R.; Kim, D. Y. Bull. Korem Chen. Soc. 2007, 28 2191. (f) Kim, S. M.; Kang, Y. K.; Cho, M. J.; Mang, I. Y.; Kim, D. Y. Bull. Korean Chem. Soc 2007, 28, 2435. (g) Lee, J. H.; Bang, H. T.: Kim, D. Y. Sinlett 2008, 1821.

8. (a) $\mathrm{Li}_{1} \mathrm{~K}$; Hii, K. K. Chem. Commm, 2003, 1132. (b) Li, K.; Horton, $\mathrm{P} . \mathrm{N}$; Hursthouse, M. B. Hii, K. K. J. Organonetallic Chen. 2003, 665, 250. For a aquapalladium complex, see (c) Shimada, T.; Bairacharya, G. B.; Yamamoto, Y. Eur. J. Org. Chem. 2005, 59 , and references cited therein. (d) Vicente, J.; Arcas, A. Cood. Chem. Rev. 2005, 249, 1135 . For Pd(II) chemistry, see (e) Tsuij, J. Palladium Reagents and Catahsts: New Perspectives for 21 st Centwr; John Willey \& Son: Chichester, 2004.

9. Typical procedure for the Diels-Alder reaction of acrylate derivatives in the presence of chiral Binap-palladium complexes: To a solution of Pd-cat. 1c $(0.01 \mathrm{mmol}, 10.8 \mathrm{mg})$ in $\mathrm{CH}_{2} \mathrm{Cl},(\mathrm{l} \mathrm{mL})$ was added acryloyl-1,3-oxazolidine-2-one $\{2 \mathrm{a}, 0.1$ munol, $14.1 \mathrm{mg}$ ). After the mixnire was cooled to $-40^{\circ} \mathrm{C}$, cyclopentadiene $(3,0.5 \mathrm{mmol}, 0.04 \mathrm{~mL})$ was added. The reaction mixture was stirred at $-40^{\circ} \mathrm{C}$ for $5 \mathrm{~h}$. The reaction mixture was quenching with saturated $\mathrm{NH}_{4} \mathrm{Cl}$ and extracted with dichloromethane. The combined organic layers were dried over $\mathrm{MgSO}_{4}$, tilter, concentrated, and purified by tlash chromatography (ethyl acetate, hexane $1: 1)$ to afford the cycloadduct 4 a $(20.1 \mathrm{mg}, 97 \%)$. 